\title{
Role of miR-155 in immune regulation and its relevance in oral lichen planus (Review)
}

\author{
YAN TAO, RUIXUE AI, YILONG HAO, LU JIANG, HONGXIA DAN, \\ NING JI, XIN ZENG, YU ZHOU and QIANMING CHEN \\ State Key Laboratory of Oral Diseases, National Clinical Research Center for Oral Diseases, \\ Department of Oral Medicine of West China Hospital of Stomatology, Sichuan University, \\ Chengdu, Sichuan 610041, P.R. China
}

Received May 24, 2018; Accepted October 4, 2018

DOI: $10.3892 /$ etm.2018.7019

\begin{abstract}
Oral lichen planus (OLP) is a chronic mucosal inflammatory disease. The World Health Organization has described it as a potentially malignant condition. The pathogenesis of OLP remains to be fully elucidated, but extensive evidence suggests that immunologic and inflammatory factors have important roles. MicroRNAs (miRs), which are small non-coding RNAs, have been reported to be involved in OLP. In particular, miR-155 is significantly upregulated in patients with OLP. miR-155 has numerous functions and is closely linked to inflammation and immune system regulation. However, in-depth studies of the mechanisms via which miR-155 is involved in OLP are currently insufficient. Considering the close association between miR-155 and immune regulation as well as the importance of immune factors in OLP, the role of miR-155 in the immune system was herein summarized with a focus on OLP. The present review provides a basis for further study of the molecular mechanisms underlying the development and progression of OLP.
\end{abstract}

\section{Contents}

1. Introduction

2. OLP and miR-155

3. Regulation of the immune system by miR-155

Correspondence to: Professor Yu Zhou or Professor Qianming Chen, State Key Laboratory of Oral Diseases, National Clinical Research Center for Oral Diseases, Department of Oral Medicine of West China Hospital of Stomatology, Sichuan University, 14 section 3 Renmin South Road, Chengdu, Sichuan 610041, P.R. China

E-mail: 812471898@qq.com

E-mail: qmchen@scu.edu.cn

Key words: oral lichen planus, microRNA-155, immune system, potential pathways, targets
4. Pathways associated with the miR-155/SOCS1 axis in the immune system

5. Research on immune factors associated with OLP

6. Conclusions

\section{Introduction}

Oral lichen planus (OLP) is a common mucosal inflammatory disease. It has the potential for malignant transformation $(1,2)$; it has been reported that $1-2 \%$ of patients with OLP develop oral squamous cell carcinoma (3). Although the pathogenesis of OLP remains to be fully elucidated, immune factors are thought to have important roles. A wide range of studies have indicated the importance of the immune response in OLP and have suggested that OLP is a T cell-mediated chronic inflammatory disease $(4,5)$. Various studies have suggested that microRNAs (miRNAs/miRs) also have an important role in the pathogenesis of OLP (6). miRNAs are short, single-stranded RNAs that do not encode proteins; they have been linked to inflammatory diseases and immune diseases via the dysregulation of target mRNA expression $(7,8)$. In an miRNA microarray analysis of mucosal tissues in patients with OLP and healthy controls, $\sim 70$ miRNAs were identified to be significantly dysregulated (6,9-11). Gassling et al (10) identified 16 miRNAs that were differentially expressed in mucosal tissues between OLP patients and healthy individuals. A total of 6 miRNAs, including miR-31, -146a, -155 and -21 , exhibited a $>2$-fold increase, while miR-923 and -30 a were downregulated in OLP patients (10). Our group has previously reviewed miRNAs associated with OLP, and it was identified that miR-155 is closely linked to cytokines associated with OLP, rendering it a strong candidate miRNA regarding the involvement in OLP (9). Arão et al (6) reported that miR-155 expression is upregulated in patients with OLP. However, the precise role of miR-155 in this disease has remained largely elusive. miR-155 is a multi-functional miRNA and is closely associated with inflammation, tumors and immune regulation (12). Considering the importance of the immune response in the pathogenesis of OLP, the present study comprehensively reviewed the role of miR-155 in immune system regulation and its potential association with OLP. The present review aims to provide a source of ideas for future research. 


\section{OLP and miR-155}

OLP is a common oral mucosal disease. Its clinical manifestations are reticular, ulcerative and plaque-like lesions (1). OLP predominately affects females with a prevalence of $0.1-4 \%$, and the World Health Organization (WHO) has defined it as a potentially malignant condition $(13,14)$. A recent meta-analysis of data from 20,095 patients demonstrated that $1.1 \%$ of cases of OLP develop oral squamous cell carcinoma (15). The pathological features of OLP are degeneration of basal cells, basement membrane disruption and a dense infiltration of lymphocytes in the sub-epithelial layer of connective tissue (16). Although the cause of OLP is remains uncertain, immune dysregulation is important in the development of this disease. $\mathrm{CD}^{+}$and $\mathrm{CD}^{+}$lymphocyte-mediated local immune responses are involved in the pathogenesis of $\operatorname{OLP}(4,17,18)$. Despite extensive research regarding the pathogenesis of OLP, the current knowledge remains limited and further studies are required. Detailed study of the pathogenesis of OLP is indispensable.

miRNAs target the 3 '-untranslated region (3'-UTR) of specific mRNAs and thereby regulate gene expression. Approximately $60 \%$ of all human protein-coding genes are predicted to contain miRNA-binding sites in their 3'-UTR. Since their discovery $<2$ decades ago, $>800$ miRNAs have been identified in mammals, and a number of them are conserved across species. Their functions are only beginning to be elucidated. The roles of miRNAs are being intensively studied in a wide range of physiological and pathological processes, including proliferation, apoptosis, differentiation and oncogenesis $(19,20)$. In addition, miRNAs have been reported to regulate the immune system as well as inflammatory networks by affecting associated signaling pathways. The abnormal expression of miRNAs leads to inflammation and immune diseases $(21,22)$. Various studies have indicated that miRNA expression profiles are altered in $\operatorname{OLP}(9,10)$. Our group has previously reviewed the miRNAs associated with OLP, revealing that miR-155 is closely linked to the cytokines associated with OLP and is therefore a good candidate for further research (9).

miR-155 is derived from an exon of the B-cell integration cluster gene. It has numerous functions and is closely linked to inflammation, tumor development and immune regulation (12). The expression of miR-155 is usually positively correlated with cytokine release. It may also target genes that encode proteins associated with inflammation (23). Furthermore, miR-155 is the first miRNA that was identified as an oncogene. In various cancer types, including breast, colon, cervical and lung cancer, miR-155 expression is increased. This miRNA is important for tumor development, functioning mainly as a tumor-promoting factor (24). Of particular importance, miR-155 has pivotal roles in immune responses. miR-155 is upregulated in activated immune cells and has a significant impact on these cells. Therefore, the abnormal expression of miR-155 results in impaired immune responses and is associated with a variety of diseases (25). Numerous studies have suggested that miR-155 is upregulated in patients with OLP. Liu et al (11) reported that miR-155 expression is upregulated in peripheral blood mononuclear cells and lesions of patients with OLP compared with that in the controls. In addition, its expression was identified to be closely associated with the severity of the disease. Hu et al (26) examined an erosive type of OLP, revealing that miR-155 negatively regulates suppressor of cytokine signaling 1 (SOCS1) in $\mathrm{CD}^{+} \mathrm{T}$ lymphocytes. A positive interaction was identified between miR-155 and interferon (IFN)- $\gamma$, which may result in a T helper type 1 cell (Th1)-mediated immune response in OLP. However, to date, in-depth research on the mechanisms by which miR-155 is involved in OLP is limited. As mentioned above, immune factors are of great significance in the pathogenesis of OLP. miR-155 is closely linked to immune system regulation. Therefore, its roles in immune system regulation and its relevance in OLP were herein systematically reviewed.

\section{Regulation of the immune system by miR-155}

miR-155 is an important immune system regulator and loss of miR-155 leads to impaired immune system responses (12). miR-155 targets specific genes to influence signaling pathways and cellular phenotypes. An increasing number of studies have focused on signaling pathways and cytokines regulated by miR-155 in the immune system, which are summarized in Table I.

Innate immune system. Innate immunity has a key role in the defence against pathogens. As the first line of defense, it provides the basis and pre-condition for the adaptive immune system (27). Various studies have indicated that miR-155 has a substantial influence on innate immunity (28).

Macrophages. When a host becomes infected, macrophages are the first to fight the pathogens. Based on their function, they may be classified into M1 and M2 macrophages (29). M1 macrophages promote inflammation and cause tissue lesions. M2 macrophages induce the restoration of tissues (30). miR-155 regulates the dynamic balance of M1 and M2 macrophages (31). SOCS1, interleukin (IL) 13 receptor $\alpha 1$ (IL13R $\alpha 1$ ) and SMAD2 are targets of miR-155 in macrophages (32-34). The polarization of M1 and M2 is controlled by SOCS1 (35). Previous studies have demonstrated that miR-155 directly regulates SOCS1 to induce macrophage activation and has an important role in innate immunity (32). IL-13, a representative Th2-type cytokine, regulates the balance between the M1 and M2 states. The activation of IL-13 and IL-13R $\alpha 1$ leads to the differentiation of Th2 types (36). miR-155 directly targets IL13R $\alpha 1$, which makes macrophages prone to differentiation into M1 cells (33). Transforming growth factor- $\beta$ (TGF- $\beta$ ) acts as an immunosuppressive and anti-inflammatory cytokine in the inflammatory process (37). SMAD2 is a key signaling factor in the TGF- $\beta$ pathway, and TGF- $\beta$ regulates gene expression via SMAD (38). Evidence has indicated that SMAD2 is a direct target of miR-155 in macrophages. miR-155 decreases TGF- $\beta$-dependent gene expression by targeting SMAD2, thereby promoting the inflammatory response (34).

Dendritic cells (DCs). DCs are specialized antigenpresenting cells that recognize, capture and respond to antigens. They are generally classified into the following types: CD11b ${ }^{+}-$like and $\mathrm{CD} 8 \mathrm{a}^{+}-$like, skin-resident Langerhans cells (LCs), plasmacytoid DCs (pDCs) and monocyte-derived 


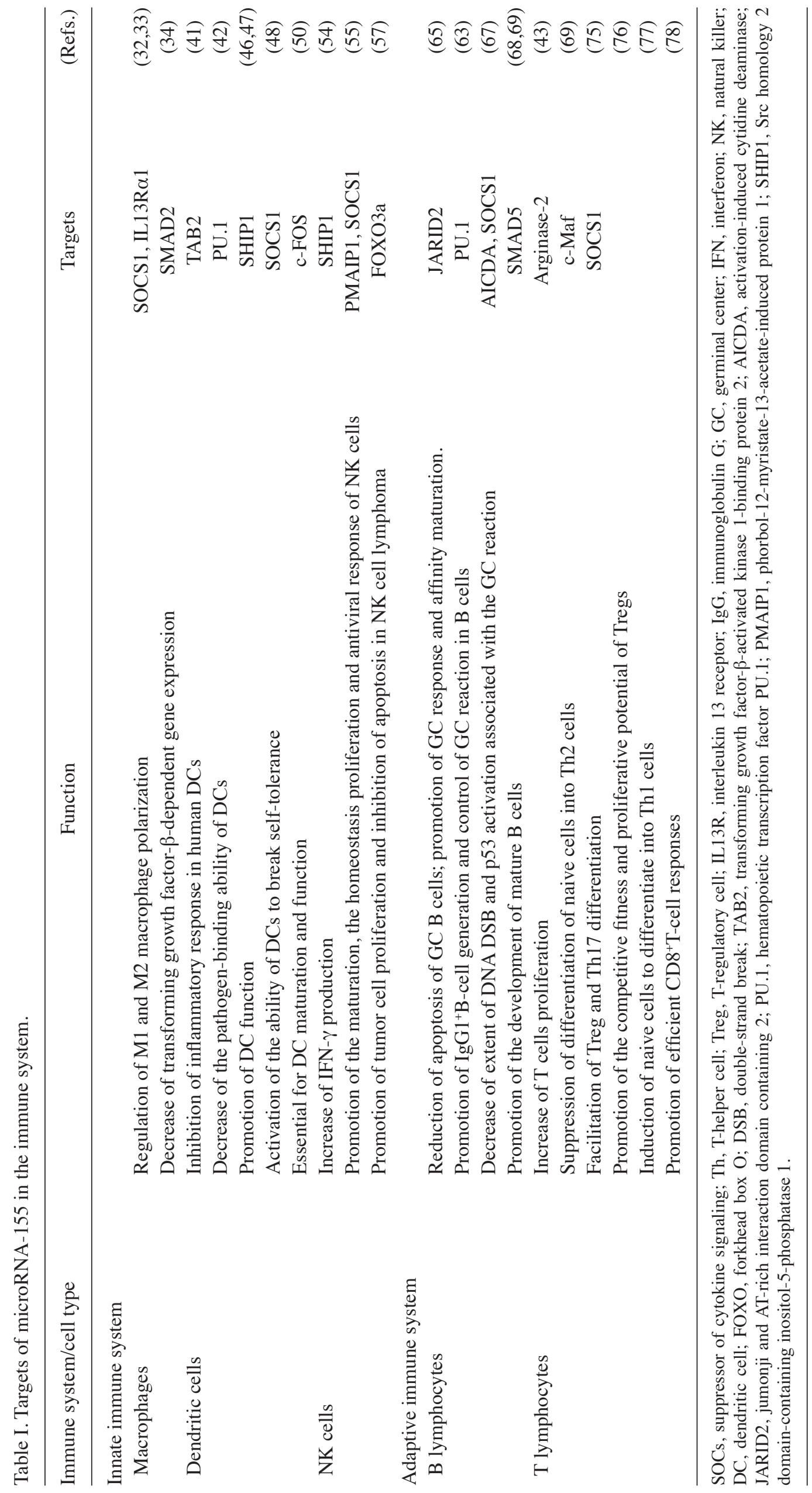


inflammatory DCs (39). As a consequence of the uptake and presentation of antigens, DCs initiate the adaptive immune response. They are the bridge that links innate and adaptive immunity (40). Numerous studies have demonstrated that DCs are controlled by miR-155; this miRNA has a key rolein the maturation and function of DCs (41-43). Martinez-Nunez et al (42) reported that the maximum miR-155 expression levels reached in DCs during maturation is 136 -fold higher in than that in immature DCs. Ceppi et al (41) monitored the expression of immunological miRNAs in activated myeloid (m)DCs and confirmed that miR-155 expression exhibited the most obvious change. Surface molecules, including major histocompatibility complex (MHC)-II, MHC-I, CD86 and CD83, are typically defining features of DC maturation. In lipopolysaccharide (LPS) or specific antigen-treated RAW264.7 cells, the expression of these molecules was induced by miR-155 (44). In addition, miR-155 knock-out mice exhibited abnormal functioning of antigen-presenting cells. The induction of T-cell proliferation and differentiation is weakened when the expression of miR-155 in DCs is decreased. IL-12, which has an important role in the maturation and function of DCs, may be induced by miR-155 (44). Collectively, these results indicate that miR-155 is highly associated with the maturation and function of DCs. Multiple targets of miR-155 associated with DCs have been identified. In the Toll-like receptor (TLR)/IL-1 transduction pathway, TGF- $\beta$-activated kinase 1-binding protein 2 (TAB2) is a crucial signaling molecule. Upon TLR4 or IL-1 receptor activation, it can induce the activation of the inflammatory response. During monocyte-derived DC maturation, the levels of TAB2 were increased. A previous study has demonstrated that TAB2 is directly regulated by miR- 155 . Accordingly, miR-155 may have an essential role in reducing the inflammatory response in human DCs by directly targeting TAB2 (41). PU.1 is a master transcription factor; it has an important role in DCs (42). DC-specific intercellular adhesion molecule-3-grabbing non-integrin (DC-SIGN), a C-type lectin, is able to bind to a large array of pathogens. It also has a substantial capacity to trigger intracellular signaling molecules that modulate DC maturation (45). PU.1 binds to motifs of the DC-SIGN promoter region to regulate its expression. Previous studies have proven that PU.1 is a target of miR-155. Martinez-Nunez (42) indicated that miR-155 indirectly inhibits DC-SIGN expression and impairs DC pathogen-binding ability by directly targeting PU.1. Src homology 2 domain-containing inositol-5-phosphatase 1 (SHIP1) is an inositol polyphosphatase that regulates DC function and efficiently triggers Th2-type responses (46). It has been evidenced that SHIP1 is a target of miR-155 (47). DCs lacking miR-155 exhibit an impaired capacity to induce a functional T-cell response, and the downregulation of SHIP1 by miR-155 may activate DC function in vivo (46). SOCS1 is able to impair the antigen recognition ability of DCs and cytokine reactions. When SOCS1 expression is inhibited, DC functions are augmented. SOCS1 is able to control IL-12 secretion and associated signaling pathways in DCs to regulate tolerance against self tumor-associated antigens (otherwise known as self-tolerance) of these cells. The inhibition of SOCS1 regulated by miR-155 is crucial for the ability of DCs to break self-tolerance (48). Cyclic AMP is able to curb the secretion of inflammatory cytokines, and c-fos is closely linked to this inhibitory process. It inhibits tumor necrosis factor (TNF- $\alpha$ ) expression and has an inhibitory role in DCs (49). It has been indicated that c-Fos mRNA is indeed targeted by miR-155. The suppression of c-Fos by miR-155 is beneficial for DC maturation and function (50).

Natural killer (NK) cells. NK cells have important roles in the defence against infection in the absence of specific immunization. They have anti-infection roles via cytolytic killing, cytokine secretion, and interactions with antigen-presenting cells and activated $\mathrm{T}$ lymphocytes. Several studies have reported that miR-155 is involved in the control of NK cell function (51). Upon stimulation, human NK cells exhibit upregulation of miR-155. Trotta et al (52) indicated that miR-155 positively regulates NK cell proliferation, development and effector functions. miR-155 also promotes IFN- $\gamma$ production in NK cells. These results demonstrate that miR-155 is important in NK cells. Several targets of miR-155 in NK cells have been identified. In human NK cells, SHIP1 negatively regulates the secretion of IFN- $\gamma$ (53). Previous studies have validated that SHIP1 is a direct target of miR-155. Another study by Trotta et al (54) demonstrated that miR-155 promotes the production of IFN- $\gamma$ in NK cells by decreasing the expression of SHIP1. Phorbol-12-myristate-13-acetate-induced protein 1 (PMAIP1-) is a member of the BH3-only subfamily and is able to induce cell apoptosis. PMAIP1 and SOCS1 have been identified as direct targets of miR-155. NK cells require miR-155 to suppress PMAIP1 and SOCS1 levels in order to increase cell survival and homeostasis. Therefore, the suppression of PMAIP1 and SOCS1 by miR-155 contributes to the promotion of NK-cell function (55). Forkhead box (FOX)O3a is able to inhibit malignant transformation and tumorigenesis (56). Studies have identified FOXO3a as a target of miR-155. In NK-cell lymphoma, overexpression of miR-155 suppresses FOXO3a expression, which increases cancer cell proliferation. The miR155/FOXO3a interaction may and serve as a useful marker and provide a theoretical basis for gene therapy for NK-cell lymphoma (57).

Adaptive immune system. A proper adaptive immune response relies on the function of $\mathrm{B}$ and $\mathrm{T}$ lymphocytes. Rodriguez et al (58) examined B and $\mathrm{T}$ lymphocyte responses in miR-155-deficient mice. They identified that immunoglobulin $\mathrm{M}(\mathrm{IgM})$ was decreased in miR-155-deficient mice. The levels of IL- 2 and IFN- $\gamma$ production were markedly lower in these mice than in healthy controls, indicating that miR-155-deficient mice were immune-deficient (58). These results clearly demonstrate that miR-155 has a crucial influence on the adaptive immune system.

B lymphocytes. Upon antigen stimulation, B cells may differentiate into plasma cells, which are able to synthesize and secrete Ig antibodies and are mainly involved in humoral immunity. The function of B cells depends on the normal expression of miR-155 (59). Once B cells are activated, the expression of miR-155 is upregulated. In miR-155 knockout mice, the number of germinal center (GC) B cells is decreased, which is indicative of defective mature B cells (60). Compared with those of wild-type equivalents, miR-155 ${ }^{-/}$mice presented with a decreased GC response and reduced production of $\operatorname{IgM}$, $\mathrm{IgG}$, and $\operatorname{Ig} \mathrm{A}$ antibodies, indicating that B-cell responses were 
impaired (61). The germinal center is a primary lymphoid follicle region. In this region, mature antibodies and memory $B$ cells are generated (62). Several studies have indicated that miR-155 is indispensable for GC responses and the production of Ig class-switched plasma cells (63). Compared with wild-type mice, miR-155-deficient mice were demonstrated to have fewer and smaller GCs (62). In addition, the secretion of antigen-specific antibodies was significantly decreased. The production of TNF- $\gamma$ and lymphotoxin (LT)- $\alpha$ was significantly reduced in miR-155/- B cells, and TNF- $\gamma$ and LT- $\alpha$ were reported to be important for GC formation (58). These results demonstrate that appropriate B-cell function depends on the normal expression of miR-155. Several potential targets of miR-155 have been identified in B lymphocytes.

GC can be distinguished to two distinct areas, called light and dark zones. Light zone B cells capture and present the processed antigen on MHC complexes to T cells. The recruitment of polycomb repressive complex 2 to its specific targets may be disturbed by Jarid2, and Jarid2 has the potential to control the proliferation and differentiation of cells (64). Studies have demonstrated that it is a target of miR-155. Nakagawa et al (65) revealed that miR-155 reduces apoptosis in $\mathrm{GC} B$ cells and promotes the survival of $\mathrm{c}-\mathrm{MYC}^{+}$light zone B cells by directly inhibiting Jarid2 expression; thus, miR-155 activates the GC response and affinity maturation. Various studies have suggested that PU.1 is required in the early stage of B-cell differentiation. It is located downstream of the B-cell receptor signaling pathway (66). In wild-type $\mathrm{B}$ cells, the expression of Pu.1 was low and difficult to detect. By contrast, its expression was readily detected in miR-155-deficient B cells. Overexpression of PU.1 may impair class-switch recombination and lead to defective generation of $\mathrm{IgG1}^{+}$cells in stimulated wild-type B cells $(59,63)$. PU.1 is presumably a negative regulator of plasma-cell differentiation and its repression by miR-155 is necessary for the GC reaction in B cells and for $\operatorname{IgG1}^{+} \mathrm{B}$-cell generation (63). Somatic hypermutation and class-switch recombination are two critical steps in the GC reaction to generate memory B cells and plasma cells. These two processes involve DNA mutagenesis and double-strand DNA breaks, which must be fine-tuned for a successful GC response (59). Bouamar et al (67) discovered an important role of miR-155 in decreasing double-strand DNA breaks and the p53-induced DNA damage response in the GC reaction. Further studies have revealed that miR-155 exerts these effects by directly targeting activation-induced cytidine deaminase (AICDA) and SOCS1 (67). In miR-155 knockdown mice, SMAD5 contributes to the impaired GC response and a decrease in the number of GC B cells. It has been demonstrated that miR-155 directly targets SMAD5, thus contributing to mature B-cell development $(68,69)$.

T lymphocytes. $\mathrm{T}$ cells are functional immune cells; they induce B cells and adjust the role of immune cells. CD4 ${ }^{+}$ $\mathrm{T}$ cells mainly consist of the following types: Th1, Th2, T-regulatory cells (Tregs) and Th17 (16). Effector CD8 ${ }^{+} \mathrm{T}$ cells are cytotoxic and secrete pro-inflammatory factors (70). The relative frequency of T-cell subgroups and relatively stable conditions are crucial for the immune system balance. Several analyses have demonstrated that miR-155 is involved in the regulation of T-lymphocyte function (71). One study has indicated that $\mathrm{CD} 4^{+} \mathrm{T}$ cells are most likely to differentiate into Th2 cells when miR-155 is knocked down (58). Next, several mechanisms and targets of miR-155 associated with the regulation of T lymphocytes will be discussed. miR-155 may affect T-cell proliferation via direct targeting of arginase (Arg)2, a semi-essential amino acid involved in multiple metabolic and cellular processes. Dunand-Sauthier et al (43) identified Arg2 mRNA as a direct target of miR-155. In activated DCs, miR-155 represses the expression of Arg2 and thus prevents excessive arginine depletion in the extracellular microenvironment, which is critical for mature DCs to initiate T-cell responses. They confirmed that miR-155 actively regulates the function of $\mathrm{T}$ cells by directly targeting $\operatorname{Arg} 2(28,43)$. c-Maf induces the differentiation of $\mathrm{T}$ cells into Th2 cells. Furthermore, it also induces Th2 cells to produce IL-4, IL-5 and IL-10 (72). Rodriguez et al (58) demonstrated that miR-155 directly targets c-Maf. CD4 ${ }^{+} \mathrm{T}$ cells with sufficient miR-155 were able to suppress the differentiation of naive cells into Th2 cells by downregulating c-Maf. SOCS1 is an important target of miR-155 in $\mathrm{T}$ lymphocytes. CD $4^{+} \mathrm{CD} 25^{+}$Tregs are a repressive Th cell subgroup and secrete anti-inflammatory cytokines. They are able to maintain self-tolerance and prevent inflammatory and immune disorders. Th17 mainly promotes the inflammatory response and contributes to immune defence $(73,74)$. Yao et al $(75)$ confirmed that miR-155 positively drives Treg/Th17-cell differentiation by directly targeting SOCS1. Furthermore, Lu et al (76) have demonstrated that miR-155 contributes to the competitive fitness and proliferation of Tregs by targeting SOCS1. In T cells, the ratio of Th1 and Th2 cell differentiation is regulated by the levels of SOCS1. Higher amounts of SOCS1 curb naive cell differentiation into Th1 cells. miR-155 can induce Th1 cell differentiation by down-regulating SOCS1 (77). CD8+ T cells are the major effector cells in the immune system. Dudda et al (78) concluded that miR-155 is a critical regulator of SOCS1 in $\mathrm{CD}^{+} \mathrm{T}$ cells. The impaired antiviral response in miR- $155^{-/} \mathrm{CD} 8^{+} \mathrm{T}$ cells may be due to increased expression of SOCS1. The downregulation of SOCS1 mediated by miR-155 is indispensable for efficient $\mathrm{CD}^{+} \mathrm{T}$-cell responses (78).

\section{Pathways associated with the miR-155/SOCS1 axis in the immune system}

The studies mentioned above indicate that the miR-155/SOCS1 axis has vital roles in immune system regulation by mediating a variety of pathways, which are illustrated in Fig. 1 and further discussed below.

The Janus kinase $(J A K) /$ signal transducer and activator of transcription (STAT) pathway. The JAK/STAT pathway mediates cell development, differentiation and apoptosis. This pathway leads to the expression of IFN-inducible genes and drives M1 polarization (35). In DCs, it regulates IL-12 production and DC maturation $(48,79)$. Furthermore, the JAK/STAT pathway contributes to Treg and Th17 differentiation, and regulates the competitive ability and proliferation of Tregs (75,76). SOCS1 negatively controls this signaling pathway. When STATs are activated, they induce the transcription of SOCS1 and, subsequently, SOCS1 proteins bind to phosphorylated JAKs to turn off the pathway (80). 


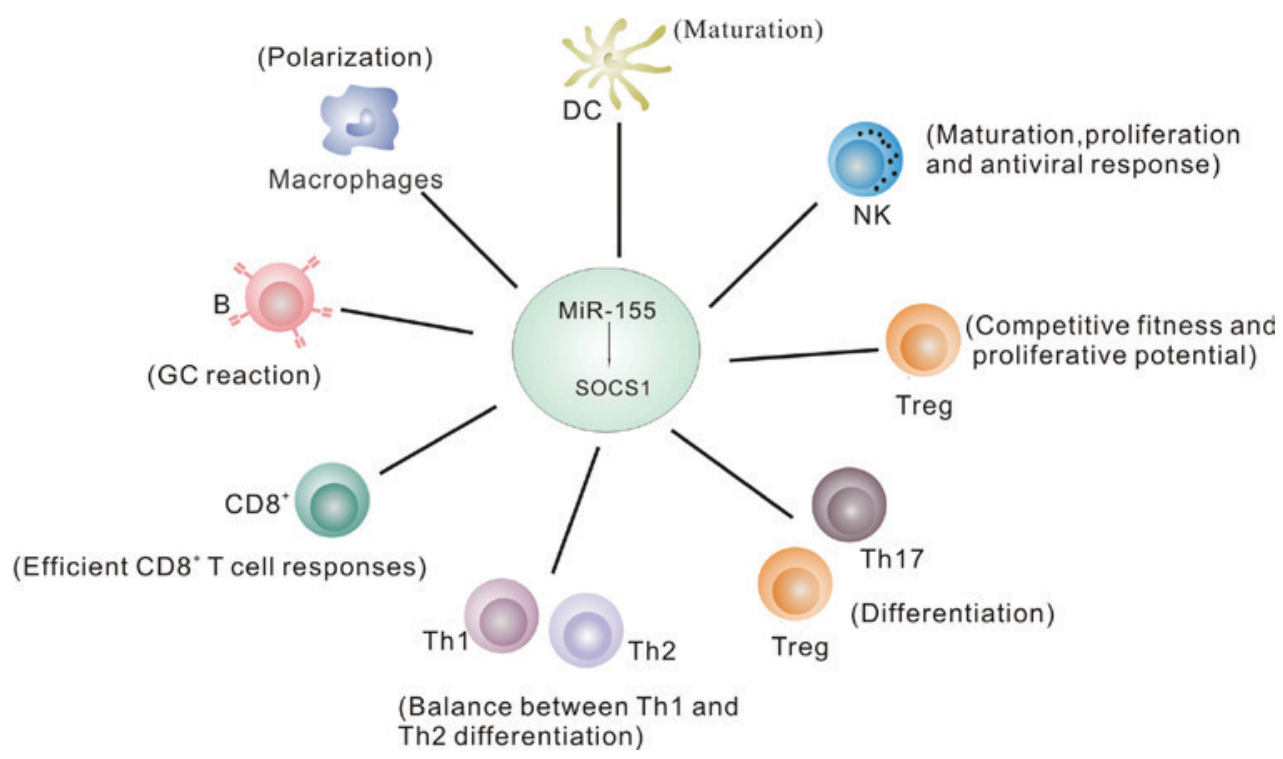

Figure 1. Summary of the role of the miR-155/SOCS1-axis in the immune system. miR, microRNA; SOCs, suppressor of cytokine signaling; NK, natural killer; DC, dendritic cell; Th, T-helper cell; Treg, T-regulatory cell; GC, germinal center.

miR-155 activates the JAK/STAT pathway by directly targeting SOCS1 (Fig. 2).

The nuclear factor $(N F)-\kappa B$ pathway. The NF- $\mathrm{NB}$ pathway is essential for the development of lymphoid organ structures and immune responses. LPS, TNF and IL-1 are able to activate the $N F-\kappa B$ pathway (81). In the innate immune system, TLRs identify viral and bacterial products, resulting in $\mathrm{NF}-\kappa \mathrm{B}$ pathway activation (82). NF- $\kappa \mathrm{B}$ molecules translocate into the nucleus, where they regulate target gene expression. In macrophages, the $\mathrm{NF}-\kappa \mathrm{B}$ pathway drives $\mathrm{M} 1$ polarization (83). In $\mathrm{T}$ cells, the activation of this pathway induces the expression of $\mathrm{NF}-\kappa \mathrm{B}$-dependent genes, which are required for T-cell activation and proliferation (84). P65 is a subunit of NF- $\kappa$ B. TIR domain-containing adaptor protein (TIRAP) and IL-1R-associated kinase 1 (IRAK) are adaptor molecules of TLR. SOCS1 is able to bind to P65, TIRAP and IRAK to suppress the $\mathrm{NF}-\kappa \mathrm{B}$ pathway. miR-155 promotes this pathway by directly targeting SOCS1 (Fig. 3) $(85,86)$.

The P53 pathway. P53 inhibits the occurrence and development of tumors. It is involved in the regulation of cell growth and differentiation. Furthermore, it promotes DNA repair. In cells under stress associated with DNA damage, hypoxia, cytokines or oncogenes, p53 accumulates in the nucleus to exert its functions (87). The maturation of B cells involves DNA mutations, double-strand DNA breaks and the activation of p53 (88). SOCS1 may combine with p53 and improve its phosphorylation, transcription and activity, providing a safeguard role in limiting the extent of DNA damage and p53 activity. MiR-155 directly targets SOCS1 and regulates p53 function to appropriate levels in B cells (67).

\section{Research on immune factors associated with OLP}

Immune factors have important roles in the pathogenesis of OLP. Numerous studies have demonstrated that immune cells are closely linked to OLP.
Innate immune system. Macrophages are normally present in the inflammatory infiltrate of lesions in chronic OLP (89). M1 macrophages induce pro-inflammatory agents, including TNF- $\alpha$, which may trigger the apoptosis of basal keratinocytes and induce basement membrane damage. In addition, M1 macrophages may increase inflammatory cells in lesions by inducing keratinocytes to secrete more chemokines (90). Therefore, macrophages actively participate in the pathogenesis of OLP. In addition, OLP-associated macrophages may induce matrix metalloproteinases (MMPs) and TNF to influence oral epithelial and sub-epithelial stromal cells. In vitro, MMPs have been demonstrated to be associated with extracellular matrix damage and activation. Furthermore, they also promote tumorigenesis. TNF is involved in tumor growth and invasion, and in cutaneous tumors, it contributes to tumor development in the early phase. Taken together, OLP-associated macrophages may participate in processes of the progression of OLP to cancer (91).

Previous studies have revealed an increase in DCs in OLP lesions, suggesting that these cells are involved in the occurrence of OLP (92-94). Santoro et al (92) observed that skin-resident LCs, pDCs and DC-SIGN ${ }^{+}$DCs were markedly upregulated in OLP lesions compared with those in a healthy control group. LCs are mainly situated in the epithelium. As a guardian of the oral mucosa, they may influence the responses of the immune system to external and endogenous antigens. Gueiros et al (93) evaluated the distribution and concentration of LCs in OLP and observed more LCs in OLP lesions than in adjacent non-inflammatory tissues and normal mucosae. Once LCs identify antigens, they may be activated to stimulate T cells. pDCs may be detected in most patients with OLP and they are principally located in single epithelial cells and the lymphoid infiltrate zone (92). One of their functions is to secrete IFN- $\alpha$. An imbalance between pDCs and IFN- $\alpha$ is linked to the occurrence of OLP (95). Yamauchi et al (94) reported that thymic stromal lymphopoietin (TSLP) receptor ${ }^{+}$mDCs are responsible for abnormal Th2 immune responses and the occurrence of OLP by regulating TSLP production. These 


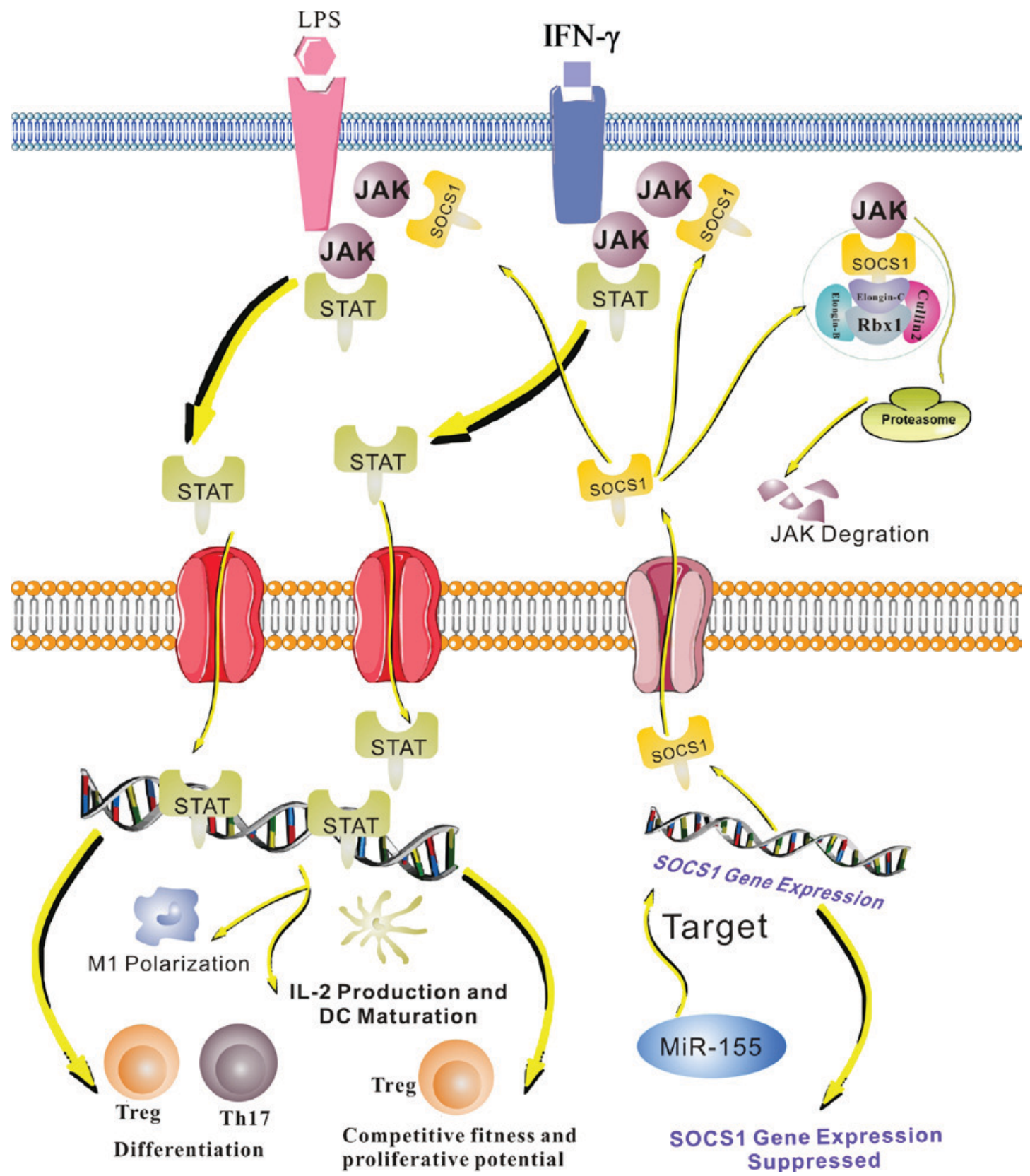

Figure 2. The JAK/STAT pathway is involved in the miR155/SOCS1 axis in the immune system. When immune cells are stimulated by cytokines, including IFN- $\gamma$ and LPS, the JAK/STAT pathway is activated. Phosphorylated STATs form a complex and are translocated to the nucleus, where they activate or repress the transcription of target genes. In macrophages, this pathway induces M1 polarization and promotes the production of tumor necrosis factor- $\alpha$, IL- 6 and IL-1 $\beta$. JAK/STAT signaling also regulates IL-12 production and DC maturation. Furthermore, the JAK-STAT pathway contributes to Treg and Th17 differentiation and regulates the competitive ability and proliferative potential of Tregs. SOCS1 negatively regulates the JAK/STAT pathway by binding to phosphorylated JAKs. miR-155 targets SOCS1 and inhibits it expression, leading to decreased binding of SOCS1 to phosphorylated JAKs. Therefore, miR-155 positively regulates the JAK/STAT pathway. JAK, Janus kinase; STAT, signal transducer and activator of transcription; IFN, interferon; LPS, lipopolysaccharide; miR, microRNA; SOCs, suppressor of cytokine signaling; Th, T-helper cell; Treg, T-regulatory cell; IL, interleukin; rbx, ring box; DC, dendritic cell.

studies suggest that DCs may be involved in the pathogenesis of OLP.

A limited number of studies have assessed the impact of NK cells in OLP. In the inflamed skin of the lichen planus, substantial NK cells may be detected. Furthermore, in lesions of OLP, they co-exist with pDCs in a chemerin-dependent manner. NK-cell dysfunction is closely linked to the occurrence of OLP (96).

Adaptive immune system. Local immune factors, including IgG and IgA responses, have defense functions in OLP. There are two types of Ig, i.e., membrane-bound receptors located on the cytomembrane of B cells and dissoluble molecules produced by plasma cells. The occurrence of OLP is thought to be associated with Ig levels. IgG and IgA are the predominant Igs in normal serum (97). The levels of IgG and IgA in OLP remain to be clarified, and differences exist among previous studies. Certain studies have identified elevated serum IgG and IgA levels in OLP (98). However, Divya and Sathasivasubramanian (97) reported that the average serum levels of $\operatorname{IgG}$ were slightly increased and the average levels of IgA were somewhat reduced in OLP compared with those 


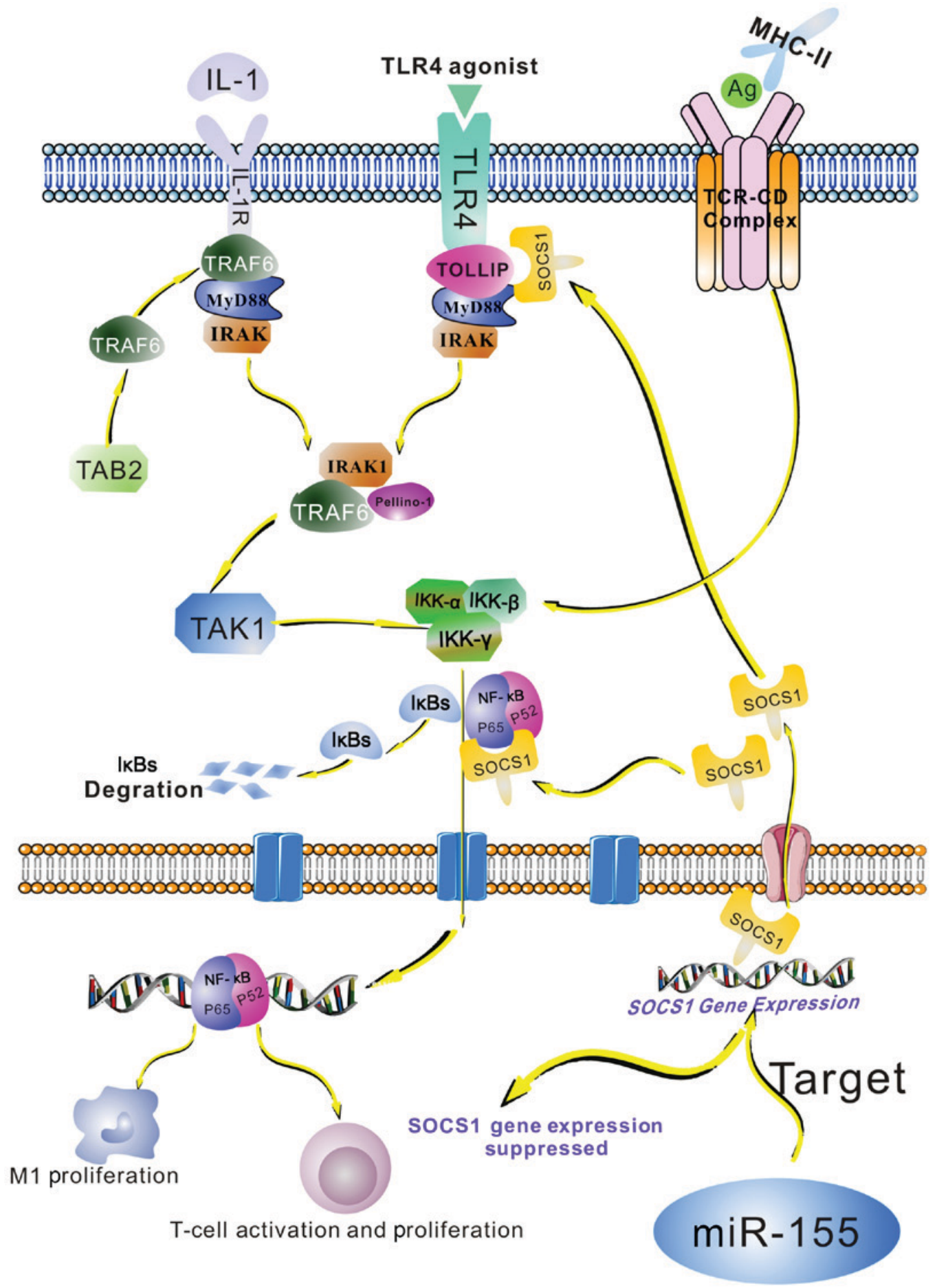

Figure 3. Role of the NF-кB pathway in the miR-155/SOCS1 axis in the immune system. Exposure of cells to lipopolysaccharide or inflammatory cytokines, including TNF or IL-1, as well as the recognition of bacterial and viral products by Toll-like receptors on immune cells, results in NF- $\kappa \mathrm{B}$ induction. The interactions between T-cell receptors and CD28 receptors with their ligands, MHC class II, and the co-stimulatory molecules CD80 and CD86 on the surface of antigen-presenting cells, trigger the NF- $\mathrm{KB}$ pathway in T-cells. NF- $\mathrm{KB}$ becomes activated and translocates to the nucleus, where it induces the expression of its target genes. This pathway may induce M1 macrophage polarization. In T-cells, it may lead to the expression of NF- $\mathrm{BB}$-dependent genes, including IL-2, IL-2R and interferon, which are required for T-cell activation and proliferation. SOCS1 may regulate NF- $\mathrm{kB}$ signaling by binding to the p65 subunit of NF- $\mathrm{kB}$, the TLR adaptor molecule TIRAP, as well as IRAK. miR-155 targets SOCS1 and inhibits its expression, therefore indirectly promoting the NF- $\mathrm{\kappa B}$

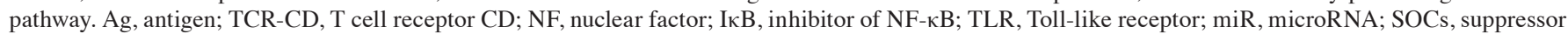
of cytokine signaling; MHC, major histocompatibility complex; IL, interleukin; IL-2R, IL-2 receptor; TIRAP, TIR domain-containing adaptor protein; IRAK, IL-1R-associated kinase 1; TOLLIP, Toll-interacting protein; MyD88, innate immune signal transduction adaptor; TRAG6, TNF receptor-associated factor 6; TNF, tumor necrosis factor; TAB2, TAK1-binding protein 2; TAK1, transforming growth factor- $\beta$-activated kinase 1; IKK, IKB kinase.

in the controls. They also reported that the amounts of salivary $\operatorname{IgG}$ and $\operatorname{Ig} \mathrm{A}$ were low in patients with OLP and healthy individuals (97). However, other studies have indicated that the levels of salivary $\operatorname{IgG}$ and $\operatorname{Ig} \mathrm{A}$ are higher in patients with OLP than those in healthy individuals (99). Ghaleyani et al (100) also observed significantly higher salivary $\operatorname{IgG}$ and $\operatorname{IgA}$ 
levels in an OLP group compared with those in a control group. Differences in the stage of OLP at which samples were obtained may explain for the differences among studies. Taken together, the observed alterations in the levels of IgG and IgA implicate Igs in the occurrence of OLP.

OLP is a chronic mucosal inflammatory disease mediated by $\mathrm{T}$ cells. The quantity of $\mathrm{CD} 4^{+} \mathrm{T}$ cells in OLP was obviously greater than that in control subjects, suggesting that $\mathrm{CD}^{+}$ $\mathrm{T}$ cells are involved in the pathogenesis of OLP. CD $4^{+} \mathrm{T}$ cells are mainly distributed in the lamina propria and subepithelial layer of OLP lesions (16). Once activated, $\mathrm{CD}^{+} \mathrm{T}$ cells bind to receptors located in the cytomembrane of $\mathrm{CD}^{+} \mathrm{T}$ lymphocytes, and they secrete pro-inflammatory cytokines. Finally, cytotoxic $\mathrm{T}$ lymphocytes are induced and contribute to chronic inflammation in local lesions (90). In addition, Tregs maintain peripheral immunological tolerance and control the proliferation of conventional T lymphocytes. A recent study indicated that, despite increased Tregs in OLP, the functions of these cells were defective. This may explain, at least in part, why the increased Tregs do not reduce the occurrence of OLP (101). In the intra-epithelial area and the basement membrane of OLP lesions, $\mathrm{CD}^{+} \mathrm{T}$ cells are present and are associated with apoptotic keratinocytes in OLP (102). These results suggested that $\mathrm{CD} 8^{+} \mathrm{T}$ cells contribute to the occurrence of OLP, and that $\mathrm{CD}^{+} \mathrm{T}$ cells induce apoptosis in keratinocytes in this disease. $\mathrm{CD}^{+} \mathrm{T}$ lymphocytes identify and potentially eliminate antigens presented by class I MHC molecules. Once $\mathrm{CD}^{+} \mathrm{T}$ cells are activated, they may induce keratinocyte apoptosis via secretion of TNF- $\alpha$ and granzyme B, as well as Fas ligand receptor expression (90). In brief, these results suggest that $\mathrm{T}$ lymphocytes are involved in the pathogenesis of OLP.

\section{Conclusions}

OLP is a chronic oral mucosal inflammatory disease and has been identified as a potentially malignant condition by the WHO. Extensive evidence suggests that immunologic factors have vital roles in the pathogenesis of OLP. An improved understanding of the mechanisms underlying OLP may provide novel approaches for potential therapeutic strategies for this disease. Several studies have indicated that miR-155 expression is significantly upregulated in OLP (6). However, the roles of miR-155, a multi-functional miRNA associated with immune system regulation, in OLP have remained to be fully elucidated. miR-155 controls macrophage differentiation and function by directly targeting SOCS1, IL13R $\alpha 1$ and SMAD2 (32-34). In DCs, miR-155 targets TAB2, PU.1, SHIP1, SOCS1 and c-Fos to regulate cell maturation and function $(41,42,46-48,50)$. In addition, miR-155 promotes the production of IFN- $\gamma$ in NK cells by decreasing the expression of SHIP1 (54). It also suppresses PMAIP1 and SOCS1 levels to increase NK cell survival and homeostasis (55). miR-155 has a crucial role in the adaptive immune system. It directly targets Jarid2, PU.1, AICDA, SOCS1 and SMAD5 to maintain an adequate B-cell function $(63,65,67-69)$. Furthermore, c-Maf, SOCS1 and Arg2 have been identified as targets of miR-155 in T lymphocytes (43,59,75-78). Previous studies have demonstrated that these immune cells actively participate in the pathogenesis of OLP. The miR-155/SOCS1 axis has important roles in immune system regulation by mediating a variety of signaling pathways, including the JAK/STAT, NF- $\mathrm{B}$ and P53 pathways. NF- $\kappa \mathrm{B}$ and associated cytokines, including IL-1 $\alpha$, IL-6, IL- 8 and TNF- $\alpha$, have beneficial effects in the inflammatory microenvironment of OLP (103). The expression of p53 is upregulated in OLP, but the reason for this remains to be determined. The increased p53 expression may be due to DNA damage occurring. In addition, the increased cell proliferation in OLP may lead to the upregulation of p53 expression. An elevated expression of p53 is thought to be associated with the pathogenesis of OLP (104).

miR-155 is upregulated in OLP, but the underlying mechanisms remain to be fully elucidated. It is well known that miR-155 is important for immune system regulation. Immune regulation has an important role in the pathogenesis of OLP. Therefore, it is possible that miR-155 is involved in the pathogenesis of OLP by regulating the immune system and associated targets, including SOCS1. Ostensibly, this interaction requires further experimental validation. With this regard, the present review provides a basis for future research and may facilitate further investigation of the pathogenesis of OLP, particularly with regard to the roles of miR-155.

\section{Acknowledgements}

Not applicable.

\section{Funding}

This study was supported by grants from the Non-profit Industry Research Specific Fund of the National Health and Family Planning Commission of China (grant no. 201502018), the National Natural Science Foundation of China (grant nos. 81470747, 81520108009, 81621062, 81200791, 81472533, 81102060 and 81270040) and the 111 Project of the Ministry of Education, China (grant no. B14038).

\section{Availability of data and materials}

Not applicable.

\section{Authors' contributions}

YT collected and analyzed all literature, and wrote the manuscript. RA and YH also collected the literature. LJ, HD, NJ and $\mathrm{XZ}$ analyzed the data. YZ and QC designed and conceived the current study. All authors have read and approved the final version of the manuscript.

\section{Ethical approval and consent to participate}

Not applicable.

\section{Patient consent for publication}

Not applicable.

\section{Competing interests}

The authors declare that they have no competing interests. 


\section{References}

1. Alrashdan MS, Cirillo N and McCullough M: Oral lichen planus: A literature review and update. Arch Dermatol Rese 308 539-551, 2016.

2. Sanketh DS, Patil S and Swetha B: Oral lichen planus and epithelial dysplasia with lichenoid features: A review and discussion with special reference to diagnosis. J Investig Clin Dent 8: e12233 2017.

3. Gonzalez-Moles MA, Scully C and Gil-Montoya JA: Oral lichen planus: Controversies surrounding malignant transformation. Oral Dis 14: 229-243, 2008.

4. Kurago ZB: Etiology and pathogenesis of oral lichen planus: An overview. Oral Surg Oral Med Oral Pathol Oral Radiol 122: $72-80,2016$.

5. Roopashree MR, Gondhalekar RV, Shashikanth MC, George J, Thippeswamy SH and Shukla A: Pathogenesis of oral lichen planus-a review. J Oral Pathol Med 39: 729-734, 2010.

6. Arão TC, Guimarães AL, de Paula AM, Gomes CC and Gomez RS: Increased miRNA-146a and miRNA-155 expressions in oral lichen planus. Arch Dermatol Res 304: 371-375, 2012.

7. Bartel DP: MicroRNAs: Genomics, biogenesis, mechanism, and function. Cell 116: 281-297, 2004

8. Ebert MS and Sharp PA: Roles for microRNAs in conferring robustness to biological processes. Cell 149: 515-524, 2012.

9. Ma H, Wu Y, Yang H, Liu J, Dan H, Zeng X, Zhou Y, Jiang L and Chen Q: MicroRNAs in oral lichen planus and potential miRNA-mRNA pathogenesis with essential cytokines: A review. Oral Surg Oral Med Oral Pathol Oral Radiol 122: 164-173, 2016

10. Gassling V, Hampe J, Açil Y, Braesen JH, Wiltfang J and Häsler R: Disease-associated miRNA-mRNA networks in oral lichen planus. PLoS One 8: e63015, 2013.

11. Liu F, Wu J and Ye F: Expression of miRNA-155 and miRNA-146a in peripheral blood mononuclear cells and plasma of oral lichen planus patients. Zhonghua Kou Qiang Yi Xue Za Zhi 50: 23-27, 2015 (In Chinese)

12. Moffett HF and Novina CD: A small RNA makes a Bic difference. Genome Biol 8: 221, 2007.

13. Sagari S, Sanadhya S, Doddamani M and Rajput R: Molecular markers in oral lichen planus: A systematic review. J Oral Maxillofac Pathol 20: 115-121, 2016.

14. Eisen D: The clinical features, malignant potential, and systemic associations of oral lichen planus: A study of 723 patients. J Am Acad Dermatol 46: 207-214, 2002.

15. Aghbari SMH, Abushouk AI, Attia A, Elmaraezy A, Menshawy A, Ahmed MS, Elsaadany BA and Ahmed EM Malignant transformation of oral lichen planus and oral lichenoid lesions: A meta-analysis of 20095 patient data. Oral Oncol 68: 92-102, 2017

16. Eisen D, Carrozzo M, Bagan Sebastian JV and Thongprasom K: Number V Oral lichen planus: Clinical features and management. Oral Dis 11: 338-349, 2005.

17. Wang H, Zhang D, Han Q, Zhao X, Zeng X, Xu Y, Sun Z and Chen Q: Role of distinct CD4(+) T helper subset in pathogenesis of oral lichen planus. J Oral Pathol Med 45: 385-393, 2016.

18. Tan YQ, Li Q, Zhang J, Du GF, Lu R and Zhou G: Increased circulating $\mathrm{CXCR}^{+} \mathrm{CD}^{+} \mathrm{T}$ follicular helper-like cells in oral lichen planus. J Oral Pathol Med 46: 803-809, 2017.

19. Friedman RC, Farh KK, Burge CB and Bartel DP: Most mammalian mRNAs are conserved targets of microRNAs. Genome Res 19: 92-105, 2009.

20. Zamore PD and Haley B: Ribo-gnome: The big world of small RNAs. Science 309: 1519-1524, 2005.

21. Raisch J, Darfeuille-Michaud A and Nguyen HT: Role of microRNAs in the immune system, inflammation and cancer. World J Gastroenterol 19: 2985-2996, 2013.

22. Contreras $\mathbf{J}$ and Rao DS: MicroRNAs in inflammation and immune responses. Leukemia 26: 404-413, 2012.

23. Cremer TJ, Ravneberg DH, Clay CD, Piper-Hunter MG, Marsh CB, Elton TS, Gunn JS, Amer A, Kanneganti TD, Schlesinger LS, et al: MiR-155 induction by F. novicida but not the virulent F. tularensis results in SHIP down-regulation and enhanced pro-inflammatory cytokine response. PLoS One 4: e8508, 2009.

24. Tili E, Michaille JJ and Croce CM: MicroRNAs play a central role in molecular dysfunctions linking inflammation with cancer Immunol Rev 253: 167-184, 2013.

25. Faraoni I, Antonetti FR, Cardone J and Bonmassar E: miR-155 gene: A typical multifunctional microRNA. Biochim Biophys Acta 1792: 497-505, 2009.
26. Hu JY, Zhang J, Ma JZ, Liang XY, Chen GY, Lu R, Du GF and Zhou G: MicroRNA-155-IFN- $\gamma$ feedback loop in CD4(+)T cells of erosive type oral lichen planus. Sci Rep 5: 16935, 2015.

27. Rasmussen SB, Reinert LS and Paludan SR: Innate recognition of intracellular pathogens: Detection and activation of the first line of defense. APMIS 117: 323-337, 2009.

28. Vigorito E, Kohlhaas S, Lu D and Leyland R: miR-155: An ancient regulator of the immune system. Immunol Rev 253: 146-157, 2013

29. Mills CD, Kincaid K, Alt JM, Heilman MJ and Hill AM: M-1/M-2 macrophages and the Th1/Th2 paradigm. J Immunol 164: 6166-6173, 2000.

30. Mantovani A, Biswas SK, Galdiero MR, Sica A and Locati M: Macrophage plasticity and polarization in tissue repair and remodelling. J Pathol 229: 176-185, 2013.

31. Ma F, Liu F, Ding L, You M, Yue H, Zhou Y and Hou Y: Anti-inflammatory effects of curcumin are associated with down regulating microRNA-155 in LPS-treated macrophages and mice. Pharm Biol 55: 1263-1273, 2017.

32. O'Connell RM, Taganov KD, Boldin MP, Cheng G and Baltimore D: MicroRNA-155 is induced during the macrophage inflammatory response. Proc Natl Acad Sci USA 104: 1604-1609, 2007.

33. Martinez-Nunez RT, Louafi F and Sanchez-Elsner T: The interleukin 13 (IL-13) pathway in human macrophages is modulated by microRNA-155 via direct targeting of interleukin 13 receptor alpha1 (IL13Ralpha1). J Biol Chem 286: 1786-1794, 2011.

34. Louafi F, Martinez-Nunez RT and Sanchez-Elsner T: MicroRNA-155 targets SMAD2 and modulates the response of macrophages to transforming growth factor- $\{$ beta\}. J Biol Chem 285: 41328-41336, 2010.

35. Wilson HM: SOCS proteins in macrophage polarization and function. Front Immunol 5: 357, 2014

36. Fuss IJ and Strober W: The role of IL-13 and NK T cells in experimental and human ulcerative colitis. Mucosal Immunol 1 (Suppl 1): S31-S33, 2008.

37. Massagué J: TGF $\beta$ signalling in context. Nat Rev Mol Cell Biol 13: 616-630, 2012.

38. Shi Y and Massagué J: Mechanisms of TGF-beta signaling from cell membrane to the nucleus. Cell 113: 685-700, 2003.

39. Turner ML, Schnorfeil FM and Brocker T: MicroRNAs regulate dendritic cell differentiation and function. J Immunol 187: 3911-3917, 2011.

40. Iwasaki A and Medzhitov R: Regulation of adaptive immunity by the innate immune system. Science 327: 291-295, 2010.

41. Ceppi M, Pereira PM, Dunand-Sauthier I, Barras E, Reith W, Santos MA and Pierre P: MicroRNA-155 modulates the interleukin-1 signaling pathway in activated human monocyte-derived dendritic cells. Proc Natl Acad Sci USA 106: 2735-2740, 2009.

42. Martinez-Nunez RT, Louafi F, Friedmann PS and Sanchez-Elsner T: MicroRNA-155 modulates the pathogen binding ability of dendritic cells (DCs) by down-regulation of DC-specific intercellular adhesion molecule-3 grabbing non-integrin (DC-SIGN). J Biol Chem 284: 16334-16342, 2009.

43. Dunand-Sauthier I, Irla M, Carnesecchi S, Seguín-Estévez Q, Vejnar CE, Zdobnov EM, Santiago-Raber ML and Reith W: Repression of arginase-2 expression in dendritic cells by microRNA-155 is critical for promoting $\mathrm{T}$ cell proliferation. J Immunol 193: 1690-1700, 2014

44. Ma YL, Ma ZJ, Wang M, Liao MY, Yao R and Liao YH: MicroRNA-155 induces differentiation of RAW264.7 cells into dendritic-like cells. Int J Clin Exp Pathol 8: 14050-14062, 2015.

45. Caparrós E, Munoz P, Sierra-Filardi E, Serrano-Gómez D, Puig-Kröger A, Rodríguez-Fernández JL, Mellado M, Sancho J, Zubiaur M and Corbí AL: DC-SIGN ligation on dendritic cells results in ERK and PI3K activation and modulates cytokine production. Blood 107: 3950-3958, 2006.

46. Lind EF, Millar DG, Dissanayake D, Savage JC, Grimshaw NK, Kerr WG and Ohashi PS: miR-155 upregulation in dendritic cells is sufficient to break tolerance in vivo by negatively regulating SHIP1. J Immunol 195: 4632-4640, 2015.

47. Costinean S, Sandhu SK, Pedersen IM, Tili E, Trotta R, Perrotti D, Ciarlariello D, Neviani P, Harb J, Kauffman LR, et al: Src homology 2 domain-containing inositol-5-phosphatase and CCAAT enhancer-binding protein beta are targeted by miR-155 in B cells of Emicro-MiR-155 transgenic mice. Blood 114: 1374-1382, 2009.

48. Evel-Kabler K, Song XT, Aldrich M, Huang XF and Chen SY: SOCS1 restricts dendritic cells' ability to break self tolerance and induce antitumor immunity by regulating IL-12 production and signaling. J Clin Invest 116: 90-100, 2006. 
49. Yoshida R, Suzuki M, Sakaguchi R, Hasegawa E, Kimura A, Shichita T, Sekiya T, Shiraishi H, Shimoda K and Yoshimura A: Forced expression of stabilized c-Fos in dendritic cells reduces cytokine production and immune responses in vivo. Biochem Biophys Res Commun 423: 247-252, 2012.

50. Dunand-Sauthier I, Santiago-Raber ML, Capponi L, Vejnar CE, Schaad O, Irla M, Seguín-Estévez Q, Descombes P, Zdobnov EM, Acha-Orbea H and Reith W: Silencing of c-Fos expression by microRNA-155 is critical for dendritic cell maturation and function. Blood 117: 4490-4500, 2011.

51. Sullivan RP, Fogel LA, Leong JW, Schneider SE, Wong R, Romee R, Thai TH, Sexl V, Matkovich SJ, Dorn GW II, et al: MicroRNA-155 tunes both the threshold and extent of NK cell activation via targeting of multiple signaling pathways. J Immunol 191: 5904-5913, 2013.

52. Trotta R, Chen L, Costinean S, Josyula S, Mundy-Bosse BL, Ciarlariello D, Mao C, Briercheck EL, McConnell KK, Mishra A, et al: Overexpression of miR-155 causes expansion, arrest in terminal differentiation and functional activation of mouse natural killer cells. Blood 121: 3126-3134, 2013.

53. Trotta R, Parihar R, Yu J, Becknell B, Allard J II, Wen J, Ding W, Mao H, Tridandapani S, Carson WE and Caligiuri MA Differential expression of SHIP1 in CD56bright and CD56dim NK cells provides a molecular basis for distinct functional responses to monokine costimulation. Blood 105: 3011-3018, 2005.

54. Trotta R, Chen L, Ciarlariello D, Josyula S, Mao C, Costinean S, Yu L, Butchar JP, Tridandapani S, Croce CM and Caligiuri MA: miR-155 regulates IFN- $\gamma$ production in natural killer cells Blood 119: 3478-3485, 2012.

55. Zawislak CL, Beaulieu AM, Loeb GB, Karo J, Canner D, Bezman NA, Lanier LL, Rudensky AY and Sun JC: Stage-specific regulation of natural killer cell homeostasis and response against viral infection by microRNA-155. Proc Natl Acad Sci USA 110 6967-6972, 2013.

56. Ikeda J, Tian T, Wang Y, Hori Y, Honma K, Wada N and Morii E: Expression of FoxO3a in clinical cases of malignant lymphoma. Pathol Res Pract 209: 716-720, 2013.

57. Ji WG, Zhang XD, Sun XD, Wang XQ, Chang BP and Zhang MZ: miRNA-155 modulates the malignant biological characteristics of NK/T-cell lymphoma cells by targeting FOXO3a gene. J Huazhong Univ Sci Technolog Med Sci 34: 882-888, 2014.

58. Rodriguez A, Vigorito E, Clare S, Warren MV, Couttet P, Soond DR, van Dongen S, Grocock RJ, Das PP, Miska EA, et al Requirement of bic/microRNA-155 for normal immune function. Science 316: 608-611, 2007.

59. de Yebenes VG, Bartolome-Izquierdo $\mathrm{N}$ and Ramiro AR: Regulation of B-cell development and function by microRNAs. Immunol Rev 253: 25-39, 2013.

60. Sandhu SK, Volinia S, Costinean S, Galasso M, Neinast R, Santhanam R, Parthun MR, Perrotti D, Marcucci G, Garzon R and Croce CM: miR-155 targets histone deacetylase 4 (HDAC4) and impairs transcriptional activity of B-cell lymphoma 6 (BCL6) in the Emu-miR-155 transgenic mouse model. Proc Nat Acad Sci USA 109: 20047-20052, 2012.

61. Clare S, John V, Walker AW, Hill JL, Abreu-Goodger C, Hale C, Goulding D, Lawley TD, Mastroeni P, Frankel G, et al: Enhanced susceptibility to Citrobacter rodentium infection in microRNA-155-deficient mice. Infect Immun 81: 723-732, 2013.

62. Thai TH, Calado DP, Casola S, Ansel KM, Xiao C, Xue Y, Murphy A, Frendewey D, Valenzuela D, Kutok JL, et al: Regulation of the germinal center response by microRNA-155. Science 316: 604-608, 2007.

63. Vigorito E, Perks KL, Abreu-Goodger C, Bunting S, Xiang Z, Kohlhaas S, Das PP, Miska EA, Rodriguez A, Bradley A, et al: microRNA-155 regulates the generation of immunoglobulin class-switched plasma cells. Immunity 27: 847-859, 2007.

64. BolisettyMT,DyG,Tam WandBeemon KL:Reticuloendotheliosis virus strain $\mathrm{T}$ induces miR-155, which targets JARID2 and promotes cell survival. J Virol 83: 12009-12017, 2009.

65. Nakagawa R, Leyland R, Meyer-Hermann M, Lu D, Turner M, Arbore G, Phan TG, Brink R and Vigorito E: MicroRNA-155 controls affinity-based selection by protecting c-MYC+ B cells from apoptosis. J Clin Invest 126: 377-388, 2016

66. Busslinger M: Transcriptional control of early B cell development. Annu Rev Immunol 22: 55-79, 2004

67. Bouamar H, Jiang D, Wang L, Lin AP, Ortega M and Aguiar RC: MicroRNA 155 control of p53 activity is context dependent and mediated by Aicda and Socs1. Mol Cell Biol 35: 1329-1340, 2015 .
68. Jiang D and Aguiar RC: MicroRNA-155 controls RB phosphorylation in normal and malignant $\mathrm{B}$ lymphocytes via the noncanonical TGF-beta1/SMAD5 signaling module. Blood 123: 86-93, 2014.

69. Rai D, Kim SW, McKeller MR, Dahia PL and Aguiar RC: Targeting of SMAD5 links microRNA-155 to the TGF-beta pathway and lymphomagenesis. Proc Natl Acad Sci USA 107: 3111-3116, 2010.

70. Zhang N and Bevan MJ: CD8(+) T cells: Foot soldiers of the immune system. Immunity 35: 161-168, 2011

71. Sanchez-Diaz R, Blanco-Dominguez R, Lasarte S, Tsilingiri K, Martín-Gayo E, Linillos-Pradillo B, de la Fuente $\mathrm{H}$, Sánchez-Madrid F, Nakagawa R, Toribio ML and Martín P: Thymus-derived regulatory $\mathrm{T}$ cell development is regulated by C-Type lectin-mediated BIC/MicroRNA 155 expression. Mol Cell Boil 37: e00304, 2017.

72. Hwang ES, White IA and Ho IC: An IL-4-independent and CD25-mediated function of c-maf in promoting the production of Th2 cytokines. Proc Natl Acad Sci USA 99: 13026-13030, 2002.

73. O'Garra A and Vieira P: Regulatory T cells and mechanisms of immune system control. Nat Med 10: 801-805, 2004.

74. Bettelli E, Korn T, Oukka M and Kuchroo VK: Induction and effector functions of T(H)17 cells. Nature 453: 1051-1057, 2008.

75. Yao R, Ma YL, Liang W, Li HH, Ma ZJ, Yu X and Liao YH: MicroRNA-155 modulates treg and Th17 cells differentiation and Th17 cell function by targeting SOCS1. PLoS One 7: e46082, 2012.

76. Lu LF, Thai TH, Calado DP, Chaudhry A, Kubo M, Tanaka K, Loeb GB, Lee H, Yoshimura A, Rajewsky K and Rudensky AY: Foxp3-dependent microRNA155 confers competitive fitness to regulatory $\mathrm{T}$ cells by targeting SOCS1 protein. Immunity 30 : 80-91, 2009.

77. Harada M, Nakashima K, Hirota T, Shimizu M, Doi S, Fujita K, Shirakawa T, Enomoto T, Yoshikawa M, Moriyama H, et al: Functional polymorphism in the suppressor of cytokine signaling 1 gene associated with adult asthma. Am J Respir Cell Mol Biol 36: 491-496, 2007.

78. Dudda JC, Salaun B, Ji Y, Palmer DC, Monnot GC, Merck E, Boudousquie C, Utzschneider DT, Escobar TM, Perret R, et al: MicroRNA-155 is required for effector CD8+ T cell responses to virus infection and cancer. Immunity 38: 742-753, 2013.

79. Huffaker TB and O'Connell RM: miR-155-SOCS1 as a functional axis: Satisfying the burden of proof. Immunity 43: 3-4, 2015.

80. Weniger MA, Melzner I, Menz CK, Wegener S, Bucur AJ, Dorsch K, Mattfeldt T, Barth TF and Möller P: Mutations of the tumor suppressor gene SOCS-1 in classical hodgkin lymphoma are frequent and associated with nuclear phospho-STAT5 accumulation. Oncogene 25: 2679-2684, 2006.

81. Pomerantz JL and Baltimore D: Two pathways to NF-kappaB. Mol Cell 10: 693-695, 2002.

82. Musikacharoen T, Matsuguchi T, Kikuchi T and Yoshikai Y: NF-kappa B and STAT5 play important roles in the regulation of mouse Toll-like receptor 2 gene expression. J Immunol 166: 4516-4524, 2001

83. Strebovsky J, Walker P and Dalpke AH: Suppressor of cytokine signaling proteins as regulators of innate immune signaling. Front Biosci (Landmark Ed) 17: 1627-1639, 2012

84. Li J, Liu Z, Jiang S, Cortesini R, Lederman S and Suciu-Foca N: T suppressor lymphocytes inhibit NF-kappa B-mediated transcription of CD86 gene in APC. J Immunol 163: 6386-6392, 1999.

85. Baetz A, Frey M, Heeg K and Dalpke AH: Suppressor of cytokine signaling (SOCS) proteins indirectly regulate toll-like receptor signaling in innate immune cells. J Boil Chem 279: 54708-54715, 2004.

86. Ryo A, Suizu F, Yoshida Y, Perrem K, Liou YC, Wulf G, Rottapel R, Yamaoka S and Lu KP: Regulation of NF-kappaB signaling by Pin1-dependent prolyl isomerization and ubiquitin-mediated proteolysis of p65/RelA. Mol Cell 12: 1413-1426, 2003.

87. Ceskova P, Chichger H, Wallace M, Vojtesek B and Hupp TR: On the mechanism of sequence-specific DNA-dependent acetylation of p53: The acetylation motif is exposed upon DNA binding. J Mol Boil 357: 442-456, 2006.

88. Guikema JE, Linehan EK, Esa N, Tsuchimoto D, Nakabeppu Y, Woodland RT and Schrader CE: Apurinic/apyrimidinic endonuclease 2 regulates the expansion of germinal centers by protecting against activation-induced cytidine deaminase-independent DNA damage in B cells. J Immunol 193: 931-939, 2014. 
89. Hirota J, Osaki T and Tatemoto Y: Immunohistochemical staining of infiltrates in oral lichen planus. Pathol Res Pract 186: 625-632, 1990.

90.Payeras MR, Cherubini K, Figueiredo MA and Salum FG: Oral lichen planus: Focus on etiopathogenesis. Arch Oral Boil 58: 1057-1069, 2013.

91. Mignogna MD, Fedele S, Lo Russo L, Lo Muzio L and Bucci E: Immune activation and chronic inflammation as the cause of malignancy in oral lichen planus: Is there any evidence ? Oral Oncol 40: 120-130, 2004.

92. Santoro A, Majorana A, Roversi L, Gentili F, Marrelli S, Vermi W, Bardellini E, Sapelli P and Facchetti F: Recruitment of dendritic cells in oral lichen planus. J Pathol 205: 426-434, 2005.

93. Gueiros LA, Gondak R, Jorge Junior J, Coletta RD, Carvalho Ade A, Leão JC, de Almeida OP and Vargas PA: Increased number of Langerhans cells in oral lichen planus and oral lichenoid lesions. Oral Surg Oral Med Oral Pathol Oral Radiol 113: 661-666, 2012.

94. Yamauchi M, Moriyama M, Hayashida JN, Maehara T, Ishiguro N, Kubota K, Furukawa S, Ohta M, Sakamoto M, Tanaka A and Nakamura S: Myeloid dendritic cells stimulated by thymic stromal lymphopoietin promote Th2 immune responses and the pathogenesis of oral lichen planus. PLoS One 12: e0173017, 2017.

95. Trucci VM, Salum FG, Figueiredo MA and Cherubini K: Interrelationship of dendritic cells, type 1 interferon system, regulatory $\mathrm{T}$ cells and toll-like receptors and their role in lichen planus and lupus erythematosus-a literature review. Arch Oral Biol 58: 1532-1540, 2013.

96.Skrzeczynska-Moncznik J, Stefanska A, Zabel BA, Kapinska-Mrowiecka M, Butcher EC and Cichy J: Chemerin and the recruitment of NK cells to diseased skin. Acta Biochim Pol 56: 355-360, 2009.
97. Divya VC and Sathasivasubramanian S: Estimation of serum and salivary immunoglobulin $\mathrm{G}$ and immunoglobulin $\mathrm{A}$ in oral pre-cancer: A study in oral submucous fibrosis and oral lichen planus. J Nat Sci Biol Med 5: 90-94, 2014.

98. Albanidou-Farmaki E, Kayavis I, Sideropoulos I, Papanayiotou P and Polymenidis Z: Serum immunoglobulins IgA, IgG and IgM, and oral lichen planus. Stomatologia (Athenai) 47: 114-120, 1990 (In Greek, Modern).

99. Sistig S, Vucicevic-Boras V, Lukac J and Kusic Z: Salivary IgA and IgG subclasses in oral mucosal diseases. Oral Dis 8: 282-286, 2002.

100. Ghaleyani P, Sardari F and Akbari M: Salivary IgA and IgG in oral lichen planus and oral lichenoid reactions diseases. Adv Biomed Res 1: 73, 2012.

101. Zhou L, Cao T, Wang Y, Yao H, Du G, Chen G, Niu X and Tang G: Frequently increased but functionally impaired $\mathrm{CD} 4+\mathrm{CD} 25+$ regulatory $\mathrm{T}$ cells in patients with oral lichen planus. Inflammation 39: 1205-1215, 2016.

102. Zhou XJ, Sugerman PB, Savage NW, Walsh LJ and Seymour GJ: Intra-epithelial CD8+ T cells and basement membrane disruption in oral lichen planus. J Oral Pathol Med 31: 23-27, 2002.

103. Georgakopoulou EA, Achtari MD, Achtaris M, Foukas PG and Kotsinas A: Oral lichen planus as a preneoplastic inflammatory model. J Biomed Biotechnol 2012: 759626, 2012.

104. Ebrahimi M, Boldrup L, Coates PJ, Wahlin YB, Bourdon JC and Nylander K: Expression of novel p53 isoforms in oral lichen planus. Oral Oncol 44: 156-161, 2008.

c) (i) $\Theta$ This work is licensed under a Creative Commons CY NG NO Attribution-NonCommercial-NoDerivatives 4.0 International (CC BY-NC-ND 4.0) License. 